\title{
VIOLÊNCIA ESCOLAR FRENTE À JUDICIALIZAÇÃO: UM ESTUDO EM ESCOLAS DE CASCAVEL - PR
}

\author{
I. K. S. ARAÚJO FILHO ${ }^{1}$, T. M. R. SCHROEDER ${ }^{2}$, C. B. M. ABREU ${ }^{3}$ e F. L. ALVES ${ }^{4}$ \\ Universidade Estadual do Oeste do Parana \\ kalil@kaliladvogados.com.br ${ }^{1}$
}

Submetido em 14/02/2018 e aceito em 29/01/2020

DOI: $10.15628 /$ holos. 2020.6936

\section{RESUMO}

Este artigo apresenta resultados de uma pesquisa realizada no Programa de Pós-graduação em Educação (PPGE) da Universidade Estadual do Oeste do Paraná UNIOESTE. O escopo foi analisar a articulação entre escolas, Conselho Tutelar e Poder Judiciário nos casos de judicialização de violência escolar. Participaram da pesquisa 10 escolas da rede pública municipal de ensino de Cascavel e 10 escolas estaduais, sendo que metade das referidas escolas foram indicadas pelo Conselho Tutelar da Região Leste e a outra metade pelo da Região Oeste. O critério de inclusão na amostra foi o de escolas com maior incidência de violências registradas em cada um desses órgãos. Entrevistou-se diretores e coordenadores pedagógicos de cada uma dessas 20 escolas com vistas a identificar os tipos de violência nelas perpetradas e os critérios para os encaminhamentos ao Conselho Tutelar, bem como a qualidade da interação entre essas instituições a partir da análise dos resultados dos casos encaminhados ao Poder Judiciário. Foram, também, entrevistados os Conselheiros responsáveis de cada região do município de Cascavel, objetivando apreender suas percepções a respeito das atuações das escolas nos episódios de violência, quais as providências por eles tomadas ao receberem esses casos e quais os efeitos dessas providências em relação à resolução do problema.

PALAVRAS-CHAVE: Conselho Tutelar, Violência Escolar, Judicialização

\section{SCHOOL VIOLENCE FACED TO JUDICIALIZATION: A STUDY IN SCHOOLS FROM CASCAVEL, PARANÁ, BRAZIL}

\begin{abstract}
This article presents results of a research carried out in the Graduate Program in Education of the State University of the West of Paraná - UNIOESTE whose scope was to analyze the relations between the school, the Guardianship Council and the Judiciary in cases of judicialization of Violence. The data were collected in 10 schools of the municipal public network of education of the city of Cascavel and 10 state schools, with half of the schools being indicated by the Guardianship Council of the Eastern Region and the other half by the West Region whose inclusion criteria were schools with higher Incidence of violence recorded in each of these Council. Pedagogical directors and coordinators of each of these
\end{abstract}

20 schools were interviewed with the purpose of identifying the perpetrated types of violence and the criteria adopted for referrals to the Guardianship Council, as well as the quality of the interaction between these institutions from the results analisys of the cases referred to the Judiciary. The Councilors responsible for each region of the municipality of Cascavel were also interviewed, with the purpose of apprehending their perceptions regarding the actions of schools in the episodes of violence, the measures taken by them to receive such cases and the effects of these measures in relation to problem resolution.

KEYWORDS: Tutelar Council. School Violence. Judiciary 


\section{INTRODUÇÃO}

Analisar o fenômeno da violência em sua complexidade não é tarefa fácil, dado que ela invade nossa vida cotidiana e exige esforços contínuos de compreensão de suas manifestações em diferentes tempos e lugares. De início, é conveniente destacar que a violência é uma constante em toda a história da civilização (MAFFESOLI, 1987), no entanto, atualmente, devido à veiculação mediática rápida, ampla e alarmante, temos a sensação de maior vulnerabilidade em relação a outros tempos históricos. Todavia, o campo da história - destacando-se a brasileira - não permite cair em tal armadilha evidenciando a constância de uma violência estrutural com diversas nuances e intensidades (VIANNA, 1999; HOLANDA, 1995; FRANCO, 1997).

Em que pese a inflação da temática no cotidiano (MAFFESOLI, 1987; DEBARBIEUX, 2006), é necessário o desenvolvimento de pesquisas de campo que objetivem a compreensão desse fenômeno multifacetado.

Para Debarbieux (2006), a violência na escola se constituiu num grande desafio pedagógico e social que vem suscitando de forma crescente o interesse de políticos e intelectuais que inflacionam a temática evidenciando as violências espetaculares e sangrentas, raras no cotidiano escolar. Esse autor também ressalta a necessidade do desenvolvimento de pesquisas empíricas com vistas a enfrentar o problema, de modo a evitar exageros quantitativos de crimes no interior da escola, e, nem, tampouco, cair no extremo de desprezar este problema.

Assim, o objetivo da pesquisa foi analisar a interação entre Conselhos Tutelares e escolas da rede pública de Cascavel - PR nos cenários de judicialização da violência escolar, além de verificar casos de atuação do Conselho Tutelar nas escolas e os efeitos práticos dessa judicialização em relação a tais casos de violência.

Vale lembrar que, no caso de incidências graves, ou melhor, de atos infracionais cometidos por alunos, é dever da escola acionar o Conselho Tutelar, órgão municipal responsável por zelar e trabalhar pela salvaguarda dos direitos da criança e do adolescente, criado junto com o ECA (Estatuto da Criança e do Adolescente), instituído pela Lei 8.069 no dia 13 de julho de 1990.

Quando ocorre um ato de violência na escola e essa se caracteriza como um ato infracional praticado pelo aluno, o Conselho Tutelar deve intervir de modo a levar o fato ao conhecimento do Poder Judiciário, para que o magistrado tome as providências determinadas em lei.

A judicialização de que tratamos neste trabalho ocorre quando um problema ou divergência entre as partes é levada ao Poder Judiciário para a proposição de uma solução ou mediação entre os envolvidos. No entanto, a decisão jurídica não necessariamente encerra o conflito, pois uma sentença pode ter o objetivo de tão somente por fim ao litígio, impedindo que esse seja novamente discutido (DINIZ, 2008, p. 205).

Sobre essa questão, primeiramente, foi analisado como é a interação entre o Conselho Tutelar e as escolas e, posteriormente, realizou-se um levantamento sobre a efetividade das medidas judiciais nos casos de violência escolar. Apresentaremos uma análise dos dados coletados correlacionando-os ao que foi mencionado nas entrevistas em relação à violência escolar, à atuação do Conselho Tutelar e à judicialização. 


\section{METODOLOGIA}

\subsection{Entrevistas e critérios de inclusão}

Trata-se de uma pesquisa de caráter quanti-qualitativo, cujos dados foram coletados por meio de entrevistas semiestruturadas gravadas e transcritas.

A entrevista, segundo Lakatos (1996, p. 79), auxilia o pesquisador a identificar e obter provas sobre os "(...) objetivos dos quais os indivíduos não têm consciência, mas que orientam seu comportamento" e possibilita ao pesquisador um contato mais efetivo com seu objeto, colaborando, assim, para uma melhor análise dos dados. As entrevistas compreenderam perguntas abertas e fechadas, permitindo ao entrevistado discorrer sobre o tema apresentado respeitando o teor das questões e o roteiro proposto, todavia, sem grande formalidade.

O roteiro de entrevistas focalizou questões referentes aos tipos de casos de violência escolar que chegam ao conhecimento do Conselho Tutelar, bem como sobre a interação entre a escola e o Conselho Tutelar e a percepção desses órgãos em relação aos casos judicializados.

Para realizar as entrevistas, os seguintes passos foram seguidos:

- Seleção de 10 escolas da rede pública municipal de ensino de Cascavel e outras 10 da rede paranaense, metade das quais foram indicadas por um dos Conselhos Tutelares, da Região Leste, e outra metade pelo Conselho Tutelar da Região Oeste, tendo-se como critério de inclusão as escolas com maior incidência de violência.

\subsection{Sujeitos da pesquisa}

- Diretores e coordenadores pedagógicos das escolas selecionadas para investigar qual a incidência de casos de violência, quais os critérios de encaminhamento ao Conselho Tutelar, como é a interação entre a escola e o referido conselho nessas circunstâncias e quais os efeitos dos casos encaminhados ao Poder Judiciário quando do retorno desses alunos à escola;

- Conselheiros responsáveis de cada região do município de Cascavel (leste e oeste), objetivando levantar suas percepções em relação a atuação das escolas nos casos de violência, quais as providências por eles tomadas ao receberem esses casos e quais os efeitos dessas providências em relação à resolução efetiva do problema. Importa destacar que na ocasião em que foi iniciado o presente trabalho, no ano de 2015, Cascavel contava com dois Conselhos Tutelares; um na região leste e outro na região oeste. No ano de 2016 foi criado um terceiro Conselho Tutelar na região sul da cidade.

As respostas e constatações sobre o tema central se deram na análise da coleta de dados das entrevistas (quanti-qualitativas) com a direção das vinte escolas participantes e dos dois Conselhos Tutelares que foram objeto da pesquisa presente, ocasião na qual também foi indagado como se dá a interação entre esses órgãos.

Nominamos cada uma das Conselheiras Tutelares como "CT-A" e "CT-B" e os diretores das vinte escolas que participaram da pesquisa de D01 a D20, sendo que as nomenclaturas de D01 a 
D10 se referem às diretoras de escolas da rede municipal e as de D11 a D20 são referentes às diretoras de escolas da rede estadual de ensino. As coordenadoras pedagógicas estão representadas por nomenclaturas que vão de C01 a C20.

\section{PERCEPÇÕES DE VIOLÊNCIA ESCOLAR E ATUAÇÃO DOS CONSELHOS TUTELARES E A JUDICIALIZAÇÃO}

Primeiramente, é importante destacar que a criança e o adolescente, de acordo com a legislação brasileira, não cometem crime e nem contravenção penal, mas sim ato infracional, conforme dispõe o ECA: "Art. 103: Considera-se ato infracional a conduta descrita como crime ou contravenção penal".

Nos casos de ocorrência de ato infracional na escola, o Conselho Tutelar deve obrigatoriamente ser acionado. Da mesma forma, se um ato de indisciplina escolar for considerado infracional, deve-se também acionar o Conselho Tutelar. Mas, frequentemente, os atos de indisciplina se referem- àqueles que descumprem o regimento interno escolar e sua resolução é de competência da equipe pedagógica da escola.

Os dados demonstraram que há um índice reduzido de violência nas escolas municipais quando comparadas com as escolas estaduais. Tal diferença foi justificada pelos entrevistados como decorrência da faixa etária dos alunos de Ensino Fundamental. Para eles, a maior incidência de violência na escola está entre os adolescentes.

Tabela 1: Existem casos de violência escolar nesta instituição?

\begin{tabular}{|c|c|c|}
\hline & SIM & NÃO \\
\hline MUNICIPAIS & $50 \%$ & $50 \%$ \\
\hline ESTADUAIS & $100 \%$ & $0 \%$ \\
\hline
\end{tabular}

Fonte: Resultado da pesquisa, elaborado pelos autores.

Charlot (2006, p. 18) assinala a importância de não generalizar todo tipo de mal-estar sofrido como violência, pois, segundo este, “(...) quando tudo é uma violência, o conceito de violência não caracteriza mais nada". Para o autor, a dificuldade para delimitar o que é violência decorre das múltiplas semânticas que circundam a palavra. Assim sendo, para compreender o fenômeno da violência, deve-se levar em conta o meio social e seus valores éticos, culturais e políticos.

Para subsidiar a tipificação dos acontecimentos que podem ser considerados como violência no espaço escolar, Debarbieux (2002) e Charlot (2006) diferenciam três tipos: violência na escola; violência à escola e violência da escola.

A violência na escola ocorre no interior da instituição, mas se relaciona a um evento externo, pois algumas violências estão diretamente relacionadas à sociedade e ao bairro onde a escola está inserida. É a violência que vem de fora para dentro da escola. Para Charlot (2006, p. 434), a violência na escola: 
[...] se produz dentro do espaço escolar, sem estar ligada à natureza e às atividades da instituição escolar: quando um bando entra na escola para acertar contas das disputas que são as do bairro, a escola é apenas o lugar de uma violência que teria podido acontecer em qualquer outro local. Pode-se, contudo, perguntar-se porque a escola, hoje, não está mais ao abrigo de violências que outrora se detinham nas portas da escola (CHARLOT, 2002, p. 434).

Diferentemente, a violência à escola se relaciona aos fatores institucionais e ocorre contra a instituição, como no caso da depredação escolar, ou, ainda, em casos de se praticar atos violentos contra aqueles que representam a escola, como os professores ou a equipe pedagógica.

Importante ressaltar que essa modalidade de violência deve ser analisada de modo conjunto à violência da escola quando as vítimas são os alunos. Tipificadas na literatura como violência institucional (GUIMARÃES, 1990; CHARLOT, 2006), a violência da escola pode se manifestar como resposta a medidas tomadas para controle e imposição da disciplina, bem como na qualidade das relações interpessoais ou, até mesmo, nos métodos de avaliação.

Para Charlot (2006, p. 435), "se a escola é largamente (mas não totalmente) impotente face à violência na escola, ela dispõe (ainda) de margens de ação face à violência à escola e da escola". Para tal enfrentamento é necessário um constante diálogo para a resolução de conflitos antes que se transformem em atos de violência.

Em alguns casos de violência da escola ou violência institucional, a escola passa a ser alvo dos mais variados tipos de violência, seja entre alunos, alunos e professores, e, frequentemente, a depredação das instalações escolares.

Um dos motivos para a ocorrência de tal fato é o de que a escola se organiza para ser um espaço democrático, mas, na prática, não atua desta forma (GUIMARÃES, 1990). Se, por um lado, a escola prevê em seu projeto político pedagógico uma organização escolar democrática, por outro lado, exerce cotidianamente mecanismos de vigilância e punição não condizentes com princípios democráticos. Tal dinâmica contraditória foi observada por Guimarães (1990) nas escolas de Campinas (SP) onde constatou a prevalência de violências institucionais por meio de controles e vigilâncias exagerados. Em face do exposto, não é profícuo estabelecer como causas de violência escolar os fatores meramente externos à escola ou, ainda, a problemas individuais dos alunos.

Deste modo, é importante considerar que certos comportamentos violentos ou inadequados dos alunos podem estar diretamente relacionados às suas insatisfações com a escola.

Tabela 2: Quantos casos de violência envolvendo alunos se verificam a cada mês em média na escola?

\begin{tabular}{|c|c|c|c|c|c|}
\hline & $\begin{array}{c}\text { Nenhum } \\
\text { caso }\end{array}$ & $\begin{array}{c}\text { De } 1 \text { a } 10 \\
\text { casos }\end{array}$ & $\begin{array}{c}\text { De } 11 \text { a } 20 \\
\text { casos }\end{array}$ & $\begin{array}{c}\text { De } 21 \text { a } 30 \\
\text { casos }\end{array}$ & $\begin{array}{c}\text { Mais de } 30 \\
\text { casos }\end{array}$ \\
\hline MUNICIPAIS & $20 \%$ & $80 \%$ & $0 \%$ & $0 \%$ & $0 \%$ \\
\hline ESTADUAIS & $0 \%$ & $30 \%$ & $20 \%$ & $30 \%$ & $20 \%$ \\
\hline
\end{tabular}

Fonte: Resultado da pesquisa, elaborado pelos autores. 
Nessa pesquisa, constatou-se que a maior incidência de casos de violência escolar se situa nas escolas estaduais. Nas escolas da rede municipal de ensino, o número de casos de violência escolar é pequeno se comparado com a rede estadual. Além disso, a equipe pedagógica das escolas municipais destacou que, quando ocorrem tais casos, esses são considerados de pequena relevância.

Tabela 3. Como é a interação entre Conselho Tutelar e escola, ou seja: como a escola percebe a atuação do Conselho Tutelar frente aos casos de violência?

\begin{tabular}{|c|c|c|}
\hline & BOA & RUIM \\
\hline MUNICIPAIS & $70 \%$ & $30 \%$ \\
\hline ESTADUAIS & $10 \%$ & $90 \%$ \\
\hline
\end{tabular}

Fonte: Resultado da pesquisa, elaborado pelos autores.

A percepção da direção escolar no quesito satisfação em relação a atuação do Conselho Tutelar é diametralmente oposta quando comparadas escolas municipais e estaduais. Inferimos que essa diferença em suas percepções se dá pelo fato de que os casos de violência escolar nas escolas municipais, além de serem esporádicos, não são considerados graves pela equipe pedagógica e diretores e, em razão disso, são resolvidos internamente. Assim, a rede municipal de ensino aciona o Conselho Tutelar com menos frequência quando em comparação à rede estadual.

Como existe um maior índice de violência escolar na rede estadual, a equipe pedagógica possui, em decorrência disso, um maior contato com o Conselho Tutelar. De acordo com o constatado nas entrevistas, a maior parte dessas escolas assinalou a dificuldade de atendimento que possuem em relação àquele, seja pela morosidade do contato com a escola, seja pela demora na devolutiva do encaminhamento realizado.

Tabela 4: Dentre os casos de violência que são levados ao conhecimento do Poder Judiciário, que tipo de melhora efetiva existe em relação ao aluno atendido pelo Conselho Tutelar?

\begin{tabular}{|c|c|c|c|}
\hline & $\begin{array}{c}\text { Não existe melhora } \\
\text { no aluno atendido }\end{array}$ & O aluno melhorou & $\begin{array}{c}\text { Não teve caso } \\
\text { judicializado/não } \\
\text { opinaram }\end{array}$ \\
\hline MUNICIPAIS & $60 \%$ & $10 \%$ & $30 \%$ \\
\hline ESTADUAIS & $60 \%$ & $40 \%$ & \\
\hline
\end{tabular}

Fonte: Resultado da pesquisa, elaborado pelos autores.

Nesse ponto, a porcentagem de descontentamento das escolas foi igual (60\%). Em relação à baixa efetividade da judicialização nos casos de violência escolar, cumpre mais uma vez destacar 
que o ponto principal é a morosidade de tal medida e a falta de aproximação do adolescente com a escola, os pais e os psicólogos.

\section{PERCEPÇÕES DE VIOLÊNCIA ESCOLAR NA REDE MUNICIPAL}

Em relação à incidência de casos de violência escolar, a maioria das respostas apontou que são poucos os casos dignos de encaminhamentos fora da escola, já que se referem ao descumprimento do regimento escolar, raramente existindo ato infracional. Esse índice quase zero de violência escolar é explicado, segundo as diretoras, por conta da idade dos alunos do Ensino Fundamental.

Além disso, a direção das escolas da rede municipal destacou que, na ocorrência de situações de violência na escola, os casos são resolvidos de forma rápida no próprio âmbito escolar. Isso se dá por compreenderem situações de violência de menor potencial ofensivo e lesivo, não se relacionando com a violação da lei e não se constituindo como atos infracionais, mas, sim, ações que desrespeitam o regimento escolar.

Os dados apontam que, nas escolas municipais, os casos de violência escolar envolvendo ato infracional se dão de forma baixa e pontual, sendo, na maioria das vezes, resolvidos no interior da escola junto com a família do agressor e a do ofendido, quando é o caso.

No que se refere às incidências de violências mais frequentes, constatou-se que são mais comuns as pequenas agressões físicas e verbais. $O$ relato das diretoras escolares sintetiza bem esse quadro:

D03 - “[...] confusão entre alunos assim, desrespeito, bullying, e acaba gerando às vezes uma briguinha, aí que a gente acaba resolvendo aqui mesmo na escola".

Ainda:

D07 - A violência em escolas do Ensino Fundamental Anos Iniciais é um pouco diferente daquelas que a gente conhece do Ensino Fundamental Anos Finais, que é aquela agressão de sangue, agressão física de vias de fato. A agressão que a gente vê entre colegas e os alunos (no ensino fundamental), é agressão as vezes um "puxão" de cabelo, as vezes um tapa, soco, que também tem peso tamanho quanto no ensino fundamental nos anos finais.

Conforme já destacado, o baixo índice de casos de violência escolar dentre os alunos da rede municipal está atrelado, principalmente, a sua faixa etária. Em relação aos casos de violência que são levados ao conhecimento do Conselho Tutelar foram raros os casos encaminhados a esse por parte das escolas municipais.

Em relação à qualidade da interação entre o Conselho Tutelar e a escola diante dos casos de violência, as diretoras das escolas municipais afirmaram, em sua maioria, que a devolutiva em relação ao atendimento prestado por parte daquele não é satisfatória.

D01 - Geralmente a gente consegue resolver aqui na escola mesmo, professora em sala de aula, quando for uma situação mais grave acaba trazendo aqui pra nós, Direção e Coordenação; mais muito raro a gente encaminhar para o conselho só em caso de extrema urgência mesmo. 
No que concerne aos casos de violência que são levados ao conhecimento do Poder Judiciário, bem como aos resultados efetivos do atendimento, as diretoras das escolas municipais afirmaram, em sua maioria, que a devolutiva em relação aos casos judicializados também é deficitária.

\section{VIOLÊNCIA ESCOLAR NA REDE ESTADUAL: PERCEPÇÕES}

De maneira diametralmente oposta à realidade do baixo índice de violência das escolas municipais, nas escolas da rede estadual, existem casos frequentes de violência escolar que podem ser tipificados tanto como meros descumprimentos do regimento interno da escola, quanto como atos infracionais, demandando a articulação entre a equipe pedagógica e o Conselho Tutelar.

Em relação aos tipos de violência mais frequentes, verificou-se agressões físicas e verbais, bem como desacato ao professor. Porém, a maior quantidade de casos se refere à violência física entre os alunos, tipificando o descumprimento do regimento interno escolar.

Para Debarbieux (2002), não devemos reduzir a violência escolar como resultado da agressividade entre os alunos, posto que a agressividade pode estar relacionada a outras violências sofridas como, por exemplo, a violência institucional, que pode gerar revoltas manifestas sob variadas formas, dentre as quais destacamos a depredação escolar e as violências de alunos contra professores. Ao imputar a origem da violência somente aos sujeitos envolvidos, perde-se a possibilidade de enfrentar o problema de forma adequada, posto se tratar de um fenômeno multifacetado.

A manifestação da violência por parte dos alunos se revela como uma possibilidade de eles terem uma visibilidade em relação às suas demonstrações de insurgências e exteriorizações de inconformismo com determinadas imposições sofridas (GADEA, 2011).

Por meio dela, parece se tornar possível o estabelecimento de um espaço de conflito, podendo-se constatar que, quanto mais performática a violência se expresse, maiores serão as possibilidades de construir espaços de visibilidade e possível interlocução (GADEA, 2011, p. 89).

Para Gadea (2011) a violência pode significar o anseio social frente aos desequilíbrios e inadequações instituídos e impostos através das normas institucionais. Essa violência como forma de linguagem é entendida por Maffesoli (1987) como um meio de exteriorização de um inconformismo referente a uma opressão imposta e vivenciada, seja de forma velada ou de forma manifesta.

Como existe um maior índice de violência escolar na rede estadual, a equipe pedagógica possui, em decorrência disso, um maior contato com o Conselho Tutelar. No entanto, a maior parte dessas escolas assinalou a dificuldade de atendimento, seja pela morosidade do contato com a escola, seja pela demora na devolutiva do encaminhamento realizado.

Em relação à interação entre o Conselho Tutelar e a escola frente aos casos de violência, a maioria dos entrevistados destacou ser essa reduzida. Foram poucos os casos de diretores que elogiaram a atuação, tendo em vista a demora na devolutiva dos casos levados a conhecimento. Essa morosidade foi justificada pelos próprios diretores escolares, posto que há um efetivo pequeno de conselheiros tutelares para atenderem todas as solicitações. 
No tocante à judicialização dos casos de violência, como ocorre a interação entre o Conselho Tutelar e a escola, bem como a atuação desse, foi destacado pela maior parte dos diretores da rede estadual a morosidade tanto no atendimento inicial, bem como a exígua efetividade de resultados obtidos pelas medidas judiciais.

D16 - [...] em geral, os resultados não são muito positivos, nós temos poucos resultados de alunos que retornam à escola e têm um pouco de melhora. Estes casos são quando não só o poder Judiciário atua, mas quando há um acompanhamento constante da família, dos Pais, [...] quando existe uma proteção maior na família, uma reestruturação familiar nós vemos resultados, agora quando só a Justiça, ou só o Conselho Tutelar atuam muitas vezes os problemas sociais [...] que esse aluno traz, as suas ânsias de casa para a escola, faz com que não tenha efetividade o trabalho que é feito.

De outro ponto de vista, as conselheiras tutelares, avaliando a atuação da escola - equipe pedagógica - nos casos de violência, destacaram que existe um grande despreparo dessa instituição para tratar com o fenômeno da violência escolar. Para elas, "as escolas não sabem lidar com esse problema". (CT A). Afirmaram, ainda, que a violência escolar é uma situação "praticamente nova" (CT B), além de mencionarem que percebem que a equipe pedagógica e a direção agem de forma insegura diante das situações de violência (CT B).

As conselheiras tutelares assinalam a falta de preparo da equipe pedagógica para tratar com o fenômeno da violência escolar, dado que as situações envolvidas são as mais diversas. No entanto, causa espanto quando uma das conselheiras considera o fenômeno da violência como "situação nova", posto que os casos de violência escolar têm incidência mundial há muitos anos e vêm sendo divulgado mais fortemente desde os anos 1990, tanto na mídia como nas pesquisas nacionais (VIANNA, 1999; GUIMARÃES, 1990) e internacionais (DEBARBIEUX, 2002; CHARLOT, 2006).

Em relação à interação da escola com o Conselho Tutelar, de acordo com a percepção das conselheiras, verificou-se que é pouco frequente. A CT B destacou como frágil o encaminhamento da escola, bem como a resolução de problemas relacionados aos episódios de violência. Enfatizou, ainda, que o Conselho Tutelar não deveria ser acionado em determinados casos e que a relação entre o referido órgão e a escola poderia ser mais aberta, reconhecendo a necessidade de aprimoramento da interação entre esses atores.

De acordo com a percepção das diretoras entrevistadas, a violência se dá principalmente pelo aumento da faixa etária dos alunos; quanto mais velhos, maior a incidência de violência em âmbito escolar.

Existe uma convergência entre as Conselheiras Tutelares no sentido de que os casos mais comuns de violência escolar são de agressões físicas e verbais entre alunos e de agressões verbais de alunos com professores.

Guimarães (2005) identificou em suas pesquisas, realizadas em Campinas - SP, nos anos 90, que alguns atos de violência praticados pelos alunos denotavam o "querer-viver" [aqui, a autora faz referência a Maffesoli (1987)], que revelam desejos de outras formas de socialidades, bem como condutas resistentes em relação a determinados modelos de controle a que estavam submetidos.

No tocante às brigas entre alunos, é dever da escola informar imediatamente as violências repetitivas e/ou com relevante gravidade ao Conselho Tutelar para que este notifique os pais ou 
responsáveis pela criança ou adolescente, visando uma interferência familiar que promova uma readequação de comportamento. O Conselho Tutelar pode aplicar advertência aos pais ou responsáveis no caso de identificação de omissão quanto ao cumprimento dos deveres inerentes ao pátrio poder, de modo a alertá-los sobre as consequências que poderão advir caso não haja uma readequação de conduta.

No que diz respeito aos casos de violência escolar que devem ser encaminhados ao Poder Judiciário, bem como à resolução efetiva do problema, as conselheiras tutelares afirmam que existe um avanço pequeno ou quase inexistente. Uma de suas críticas e, também, de boa parte dos diretores escolares, refere-se à morosidade de atuação desse Poder. Pontuaram, ainda, que essa demora gera um descrédito em relação às medidas aplicadas.

Além disso, em relação à judicialização, as conselheiras pontuaram que o adolescente se sente fortalecido quando, após ser levado a cumprir uma medida judicial, retorna à escola em decorrência da determinação do juiz de que deve nela permanecer, descredibilizando, dessa forma, a equipe pedagógica escolar.

Quanto à atuação do Poder Judiciário na resolução dos problemas de violência, os dados revelaram que, além da morosidade em relação à devolutiva para o Conselho Tutelar e para a escola, observa-se, também, que, após o procedimento judicial, o aluno atendido não apresenta nenhuma mudança que melhore a qualidade de sua convivência na escola.

Em relação aos problemas da judicialização, Kelsen (1996) considera que a ordem jurídica surge como instrumento de coação em detrimento de uma conduta apresentada, independente da vontade das partes. Em relação a esta coação, afirma que:

\begin{abstract}
Na medida em que o ato de coação estatuído pela ordem jurídica surge como reação contra a conduta de um indivíduo pela mesma ordem jurídica especificada, esse ato coativo tem o caráter de uma sanção e a conduta humana contra a qual ele é dirigido tem o caráter de uma conduta proibida, antijurídica, de um ato ilícito ou delito - quer dizer, é o contrário daquela conduta que deve ser considerada como prescrita ou conforme ao Direito, conduta através da qual será evitada a sanção (KELSEN, 1996, p. 37).
\end{abstract}

Kelsen (1996) alerta para o fato de que nem sempre a norma atende a eficácia para qual é criada. É o que se observa em relação às aplicações das medidas socioeducativas, que não coíbem a prática de novos atos infracionais, como foi constatado nas entrevistas. Em verdade, frequentemente, o agente transgressor comete novos atos infracionais, seja pela inoperância dos órgãos do Estado, seja pela total ineficácia da sanção aplicada ao referido agente.

Carnelutti (2007), refletindo sobre o tema, aponta o total fracasso no campo da reabilitação do indivíduo atendido pela ação penalizadora do Estado, ou, no caso do adolescente, pela medida de segurança. Nesse sentido, destaca o autor que:

Se o direito penal não estivesse, como está, em seus primeiros passos e, portanto, se os remédios para o delito não fossem tão rudimentares, deveriam ser diferentes pelo menos as medidas de segurança em um caso e em outro. Por desgraça, enquanto se conseguiu certo progresso em Direito Penal na área de diagnóstico do delito, há muito, senão tudo, por fazer na área da reabilitação (CARNELUTTI, 2007, p. 56).

Assim, como o Direito determina atos de coação para o transgressor, constata-se que as coações ou reprimendas aplicadas, na maioria das vezes, não surte efeito positivo naquele que está por receber a pena, ou, no caso do adolescente infrator, a medida socioeducativa, como visto 
anteriormente. Nesse sentido, como destacado, percebe-se que existe um descrédito tanto da família quanto dos alunos atendidos pela judicialização em relação às medidas aplicadas.

\section{CONSIDERAÇÕES FINAIS}

Um passo importante para uma maior harmonização nas relações interpessoais em âmbito escolar diz respeito a ações efetivas na escola com os alunos, tendo como objetivo a significação do ensino e do espaço escolar.

Os resultados da presente pesquisa indicam que o Conselho Tutelar, por meio de seus representantes, deve estar cada vez mais preparado e sensível às questões técnicas e procedimentais de seu ofício, sendo imprescindível que o poder público implemente meios e instrumentos para uma maior integração entre esse órgão, as escolas e as famílias dos alunos.

As constatações na ocasião da coleta e da análise de dados, tanto em relação aos Conselhos Tutelares, quanto às escolas, no tocante a judicialização, apontam que o moroso caminho percorrido pela medida judicial está longe de ser a solução mais próxima da eficácia no tratamento da redução da violência escolar. Ao contrário, a judicialização se mostra frequentemente como uma medida ineficaz e que pode banalizar atos violentos, ante a inoperância de se resolver e/ou minimizar o problema.

Antes de se adentrar no tema da judicialização, constatou-se pouca interação entre os órgãos pesquisados. A falta de sinergia pode distanciar a possibilidade de uma maior harmonização entre escola e Conselho Tutelar, e, mais do que isso, pode até dificultar uma ação conjunta entre esses na tentativa de resolver o problema apresentado.

As conselheiras tutelares destacaram que os alunos atendidos e encaminhados ao Poder Judiciário não apresentam nenhuma melhora de comportamento quando retornam à escola. Ao invés disso, os alunos retornam com um descaso ainda maior em relação à escola e à obediência das regras de convivência escolar e social.

É importante, então, que seja ofertada uma sólida formação teórica e prática aos profissionais que atuam na equipe pedagógica das escolas para o enfrentamento e a elaboração de estratégias para a prevenção de violência escolar. Da mesma forma, cabe ao Conselho Tutelar uma atuação mais efetiva, assumindo seu papel legal frente as demandas das escolas.

Verificou-se que a judicialização não é a medida mais acertada em relação ao problema da violência escolar. Nesse raciocínio, Dimoulis (2011) alerta para a existência de uma "crise no Direito moderno", haja vista que o Direito vem falhando nas tentativas de pacificação e harmonização social. Segundo o autor, "um direito impotente perante a realidade social perde sua razão de ser; simplesmente 'não serve'. Isso ocorre quando o direito não atinge a regulamentação das relações sociais, perdendo assim sua credibilidade e até, ainda, a sua legitimidade" (DIMOULIS, 2011, p. 259).

Seja pela questão da morosidade, seja pela reduzida condição de resolver com efetividade o problema das infrações legais, a judicialização não é o meio mais eficaz para combater a violência escolar. Constatou-se que uma interação mais qualificada entre as escolas, o Conselho Tutelar, as famílias e os alunos poderia ser mais significativa para a diminuição ou solução do problema das violências nas escolas. Ademais, a implementação de políticas públicas para uma formação continuada dos profissionais da educação e dos conselheiros tutelares contribuiria para uma atuação consoante às reais necessidades das crianças e dos adolescentes atendidos. 
Cabe ressaltar, finalmente, que a judicialização de violências que envolvem alunos possui pontos nevrálgicos a serem compreendidos em suas peculiaridades e especificidades não para justificá-las, mas para aprimorar as atuações da escola, do Poder Judiciário e dos Conselhos Tutelares.

\section{REFERÊNCIAS}

Brasil. R. F. (1990). Estatuto da Criança e do Adolescente. Lei 8069 promulgada em 13 de julho de 1990.

Carnelutti, F. (2007). O Delito. 1. ed. São Paulo: Editora Rideel.

Charlot, B. (2006). Cotidiano das escolas: entre violências. Prefácio. Brasília, UNESCO.

Debarbieux, E. (2006) Violência na escola: um desafio mundial? Lisboa: Instituto Piaget.

Dimoulis, D. (2011). Manual de introdução ao estudo do direito: definição e conceitos básicos, norma jurídica... 4. ed. rev. Atual. E ampl. São Paulo: Editora Revista dos Tribunais.

Diniz, M. H. (2008). Compêndio de introdução à ciência do direito. 19. ed. rev. e atual. São Paulo: Saraiva.

Franco, M. S. C. (1997). Homens livres na ordem escravocrata. São Paulo: Fundação Editora da UNESP.

Gadea, C. A. (2011). A violência e as experiências coletivas de conflito. Revista Crítica de Ciências Sociais. Online, v. 92, p. 75-98, mar.

Guimarães, A. M. (1990). A depredação escolar e a dinâmica da violência. Campinas: Universidade Estadual de Campinas, 1990: 471 f. Tese (Doutorado em Educação) - Programa de PósGraduação em Educação, Faculdade de Educação, Universidade Estadual de Campinas, Campinas.

Guimarães, A. M. (2005). A dinâmica da violência escolar: conflito e ambiguidade. 2. ed. Campinas: Autores Associados.

Holanda, S. B. (1995). Raízes do Brasil. São Paulo: Companhia das Letras.

Kelsen, H. (1996). Teoria pura do direito. 5a ed. São Paulo: Martins Fontes.

Maffesoli, M. (1987). Dinâmica da violência; [tradução de Cristina M. V. França]. São Paulo: Edições Vértice: V. 7.

Rossato, L. A. (2012). Estatuto da criança e do adolescente comentado. Lei 8.069/1990, artigo por artigo. 4a ed. São Paulo: Revista dos Tribunais.

Vianna, O. (1999). Instituições políticas brasileiras. Brasília: Conselho Editorial do Senado Federal. 